\title{
A QUESTÃO DA (IM)POSSIBILIDADE DA REALIDADE EXTERIOR EM ARTHUR SCHOPENHAUER E MARTIN HEIDEGGER
}

THE QUESTION OF THE (IM) POSSIBILITY OF EXTERNAL REALITY IN ARTHUR

SCHOPENHAUER AND MARTIN HEIDEGGER

MOREIRA, Gilvanio ${ }^{1}$

(UFRN)

\section{RESUMO}

O artigo tem o objetivo de retomar, introdutoriamente, o "problema" da (im)possibilidade da realidade exterior à luz dos pensadores alemães Arthur Schopenhauer e Martin Heidegger. Neste, procura-se recolocar o debate da questão elencada acima, observando-se algumas nuances quanto ao problema reposto pela filosofia moderna ao mesmo tempo em que faz uma breve alusão ao período contemporâneo, isto em se tratando de um pequeno recorte apresentado pelo pensador alemão Martin Heidegger quanto à questão do absurdo de um "sujeito sem mundo" anunciado no $\int 43$ de seu tratado Ser e Tempo (1927). Para tal, no primeiro momento abordaremos o modo como o filósofo frankfurtiano, Arthur Schopenhauer, anuncia a noção de "realidade" (Wirklichkeit), esta, segundo ele, posta para, pelo e no entendimento. Já no segundo momento, partiremos da demonstração do $\ 43$ do tratado Ser e Tempo (GA 2) onde Heidegger apresenta sua análise fenomenológica do tal fenômeno da "realidade exterior" em confronto com uma pequena passagem da Crítica da Raz̧ão Pura do filósofo alemão, Imannuel Kant.

Palavras-chaves: Realidade; Efetividade; Mundo; Representação; Dasein.

\begin{abstract}
The article aims to return, introductively, to the "problem" of the (im) possibility of external reality in the light of the German thinkers Arthur Schopenhauer and Martin Heidegger. In this, we seek to reinstate the debate on the issue listed above, observing some nuances regarding the problem restored by modern philosophy while making a brief allusion to the contemporary period, this being a small section presented by the German thinker Martin Heidegger on the question of the absurdity of a "subject without a world" announced in $\ 43$ of his treatise, Being and Time (1927). For that, in the first moment we will approach the way in which the Frankfurt philosopher, Arthur Schopenhauer, announces the notion of "reality" (Wirklichkeit), which, according to him, is to, by and in the understanding. In the second moment, we will start from the demonstration of $₫ 43$ of the treatise Being and Time (GA 2) where Heidegger presents his phenomenological analysis of the phenomenon of "outer reality" in confrontation with a short passage from the Critique of Pure Reason by the German philosopher, Imannuel Kant.
\end{abstract}

Keywords: Reality; Effectiveness; World. Representation, Dasein.

1 Doutorando em Filosofia pela Universidade Federal do Rio Grande do Norte (UFRN). Vinculado ao departamento de Filosofia (PPGFIL). E-mail: giovanifilosofia@ gmail.com 


\section{Considerações iniciais}

A discussão sobre o "problema" da realidade exterior ou mundo exterior há muito que toma conta da história do pensamento, da história da filosofia. Seja por meio do acanhado esboço elaborado pelos pensadores mais antigos ou, ainda, pelos exegetas medievais, a questão ganha um determinado lugar. Não obstante todos estes esforços que foram despendidos para medir o tamanho do tal "problema" ou questão, nada de tão significante pôde ser aferido. Para além disto, de resto, a questão é colocada de lado ou, no máximo, canhestramente elaborada sem atingir grandes resultados.

Por certo, tal empreitada apenas ganha força no chamado período da filosofia moderna. Com efeito, é com a filosofia cartesiana que o problema da realidade exterior vem à tona para ocupar um espaço dentro da Teoria do Conhecimento, ainda na modernidade, posteriormente retomada por outros filósofos, entre eles Imannuel Kant (1724-1804) e Arthur Schopenhauer (1788-1860).

Dessa forma, é somente a partir do período da abertura da filosofia na modernidade - com as leituras e escritos do filósofo francês, René Descartes (1596-1650) - que teremos um maior tratamento para a questão da (im)possibilidade da existência dos objetos externos ou mundo exterior. A contar daqui, tal estudo estende-se até a contemporaneidade passando a render novas e significativas "notas" como é o caso da retomada do "problema" da realidade comentada por pensadores como Martin Hedeigger.

Não obstante, uma dessas importantes contribuições também aparece na obra do filósofo alemão Arthur Schopenhauer, nele, a noção de realidade (Wirklichkeit) ganhará contornos que até ali não tinham sido apontados.

Assim, com o intuito de apresentar parte do tratamento filosófico dado a questão da "realidade" por parte dos pensadores Arthur Schopenhauer e Martin Heidegger e lançar algumas considerações sobre o modo como o senso ou a doxa cotidiana trata a discussão, seguiremos a estrutura de trabalho: (I) A questão da representação e realidade em Arthur Schopenhauer e (II) O "Realismo ingênuo" e a demonstração fenomênica de Ser e Tempo sobre a questão da possibilidade de um "mundo exterior". Para tanto nos valeremos de alguns textos de comentadores e, essencialmente, das obras: Ser e Tempo; O Mundo como Vontade e como Representação; Fragmentos sobre a História da Filosofia - Precedido de Esboço de uma História da Doutrina do Ideal e do Real e a Crítica da Razão Pura. 


\section{A questão da representação e realidade em Arthur Schopenhauer}

Talvez não seja um tanto apressado afirmar que o problema da realidade externa ou do mundo exterior encontre seu fio condutor a partir da filosofia moderna e isto porque "nem os filósofos da antiguidade, nem os escolásticos parecem ter chegado a uma consciência clara desse problema filosófico". ${ }^{2}$

Nisto consta que o chamado "problema da realidade exterior" ganha força com a ideia cartesiana de que todo objeto do conhecimento reside na ideia e que, dessa forma, faz necessário duvidar daquilo que até a idade moderna chamava-se "realidade" (Realität).

Nesse contexto, o filósofo do "cogito" tende a acreditar que todos os dados que nos são fornecidos pelo mundo exterior limitam-se a nossa mente e que, nesse sentido, podemos apenas ter a certeza de que o que há, faz-se apenas a partir de nossa consciência. Sobre esse modo de tratamento da questão da realidade exterior nos assevera o filósofo Arthur Schopenhauer:

\footnotetext{
Depois que a reflexão necessária a esse objetivo foi despertada em Descartes, quando ele foi tomado pela verdade de que, antes de mais nada, estamos limitados à nossa consciência e de que o mundo nos é dado unicamente como representação: com sua conhecida expressão dubito, cogito, ergo sum, ele quis ressaltar a única certeza da consciência subjetiva, em oposição à problemática de todo resto. Desse modo, revelou o abismo existente entre o subjetivo ou ideal e o objetivo ou real e expressou essa tese na dúvida a respeito da existência do mundo exterior: simplesmente com seu mísero expediente para sair dela a saber, afirmando que o amado Deus por certo não nos irá enganar -, mostrou quão profunda e difícil é a solução desse problema. ${ }^{3}$
}

Decididamente, com Descartes, se inicia uma "querela" que durará séculos a respeito do problema da (im)possibilidade da existência das coisas fora de nós. Com efeito, a partir deste, o tema em tela é reaberto pelos filósofos posteriores. Assim, algo não muito diferente acontece nas meditações de Berkeley e Hume, afinal, tanto um quanto o outro depositam seus esforços em suas investigações no sentido de demonstrar que a realidade, enquanto tal, não seria outra coisa senão o objeto das nossas percepções, "ser e ser percebido".

Que Berkeley já havia anunciado que os objetos ditos "externos" são, na verdade, uma percepção projetada por meio da ideia e sentido não retira o problema de cena. Nesse intercurso, apesar de incipiente, segundo Schopenhauer, uma das primeiras tentativas de resolução do problema do mundo exterior é dada por Espinosa4, contudo, "por ter partido dos conceitos da

\footnotetext{
${ }^{2}$ SCHOPENHAUER, Fragmentos sobre a história da filosofia - precedido de Esboço de uma história da doutrina do ideal e do real. São Paulo. Martins fontes, 2007, p. 4.

${ }^{3}$ Ibidem, p. 5.

${ }^{4}$ Conferir crítica de Schopenhauer à Espinoza, leitor de Descartes, em Fragmentos sobre a história da filosofia

- precedido de Esboço de uma história da doutrina do ideal e do real. São Paulo. Martins fontes, 2007.
} 
filosofia cartesiana"”, o filósofo, “em sua exposição, incorre não apenas em muita obscuridade e motivos para equívocos, mas consequentemente, também em muitos paradoxos flagrantes, falácias manifestas e em tais absurdos e contradições". ${ }^{6}$

Para o filósofo de Frankfurt é apenas com Kant que o problema ganha uma envergadura mais rigorosa, pois "constatando que a extensão ou a espacialidade, encontra-se unicamente na representação e, portanto, está ligada a ela, uma vez que todo o espaço é a mera forma da representação" ${ }^{7}$, igualmente, "não pode existir, e por certo não existe, nenhuma extensão independente da nossa representação". ${ }^{8}$

Seguindo a trilha do filósofo alemão Immanuel Kant - considerando aqui suas diferenças básicas - Schopenhauer se apoiará no idealismo transcendental para não apenas fundamentar sua tese sobre O Mundo como Vontade e Representação, como também, nesse percurso, demostrar que a realidade, ou seja, a efetividade (Wirklichkeit) não é outra coisa senão aquilo que é manifestado pelo entendimento e que nos é dado como representação. Isto porque aquilo de que a matéria é matéria, isto é, a causalidade existe apenas para o entendimento, "pois ambas são uma coisa só, por seu turno, toda causalidade, portanto toda matéria, logo a efetividade inteira, existe só para o entendimento, através do entendimento, no entendimento". 9

Se, para o filósofo de Königsberg, o transcendental - enquanto formas a priori da sensibilidade e intelecto - apresenta relação direta com as condições de possibilidade do conhecimento da experiência possível; para fundamentar sua tese de que o efetivo é fundamentado no entendimento, o filósofo de Frankfurt irá percorrer as estruturas a priori do entendimento, isto é, do transcendental, abertas pela filosofia kantiana. De fato:

\footnotetext{
Schopenhauer segue os passos de Kant, e na sua teoria da representação, exposta no primeiro livro de sua obra magna, considera que a representação do indivíduo não passa de fenômeno formado com os dados da sensibilidade. A coisa-em-si mesma é inacessível à mera intuição empírica. Porém, o filósofo opera uma mudança no kantismo. Sensibilidade e entendimento não são nitidamente separados. O entendimento abriga em si apenas uma categoria, a de causalidade, e não doze, como em Kant. ${ }^{10}$
}

Quer dizer, apesar de operar com as categorias do idealismo transcendental kantiano, Schopenhauer toma a noção de representação, enquanto fenômeno possibilitado pelos dados da sensibilidade/entendimento, porém com uma diferença básica e mais simples, pois ao invés de

\footnotetext{
${ }^{5}$ Ibidem, p. 14.

${ }^{6}$ Ibidem, p. 15.

${ }^{7}$ Ibidem, p. 15.

${ }^{8}$ Ibidem, p. 15.

${ }^{9}$ SCHOPENHAUER, A. O mundo como vontade e como representação. São Paulo: Editora UNESP, 2005 , p. 53.

${ }^{10}$ BARBOSA, J. Modo de conhecimento estético e mundo em Schopenhauer. Trans/Form/ Ação, (São Paulo), v.29(2), 2006, p. 35.
}

Cadernos Cajuína, V. 5, N. 1, 2020, p. 165-177. 
problematizar os dados sensíveis apartados do entendimento, ele os toma como co-originários e dependentes. "A economia agora feita encontra justificativa no próprio Kant, pois este, todas as vezes que fornece um exemplo rigoroso de operação das categorias, sempre recorre à causalidade" ${ }^{11}$ Desse modo, "as formas da sensibilidade, espaço e tempo, são alocadas no próprio entendimento, ao lado da causalidade, que os vincula". ${ }^{12}$

Com tal manobra, o filósofo trabalha com as formas: tempo, espaço e causalidade, demonstrando como este princípio de razaão toma os dados fornecidos pela sensibilidade como explanado na passagem:

O entendimento intui diretamente, adquire um caráter sensível e, quando as sensações lhe são fornecidas, as toma como um efeito, para, via causalidade, remontar temporalmente até a sua origem, posicionando-as no espaço como representação intuitiva, objeto empírico constituído, figura. ${ }^{13}$

Nesse sentido, "a causalidade, ao vincular espaço e tempo no entendimento, possibilita portanto a percepção do mundo, já que a própria matéria não passa de causalidade”"14, ou seja, "o seu ser é o seu fazer-efeito, wirken, e a realidade seria mais apropriadamente chamada de efetividade, Wirklichkeit, isto é, um fazer-efeito do sujeito que a representa". ${ }^{15}$ Esse "fazer-efeito" (wirken) ou, em outras palavras, a causalidade, "é precisamente o que Schopenhauer denomina o material, ou seja, o conteúdo de nossas representações, a realidade (Wirklichkeit) submetida, ou melhor, constituída segundo as formas do tempo e do espaço". ${ }^{16}$

Ao usar uma "certa medida teórica" do idealismo transcendental kantiano, Schopenhauer não somente refaz parte do esquema da Estética Transcendental como também reelabora a noção de representação. "O que existe para o conhecimento, portanto, o mundo inteiro, é tão somente objeto em relação ao sujeito, intuição de quem intui, numa palavra, representação". ${ }^{17} \mathrm{O}$ erro de Kant consistiu, segundo Schopenhauer, em não ter considerado esse princípio. Com efeito:

$\mathrm{Na}$ contramão de toda a tradição filosófica, o entendimento é apresentado como uma faculdade comum a todos os animais. Mais do que isso, perde seu sentido autêntico a noção de "sensibilidade pura" no que concerne à percepção de objetos, pois as formas kantianas da sensibilidade (tempo e espaço), apresentadas em sua Estética Transcendental, não são bastantes para tanto; assim, o conhecimento sensível incorpora uma única das

${ }^{11}$ Ibidem, p. 35.

${ }^{12}$ Ibidem, p. 35.

${ }^{13}$ Ibidem, p. 36.

${ }^{14}$ Ibidem, p. 36.

15 Ibidem, p. 36.

${ }^{16}$ MORAIS, DAX. O idealismo transcendental segundo Schopenhauer: de Berkeley para além de Kant. In: Rev. Filos., Aurora, Curitiba, v. 30, n. 49, p. 42-63, jan./abr. 2018, p. 58.

${ }^{17}$ SCHOPENHAUER, 2005, p. 43. 
categorias kantianas do entendimento (a causalidade) e despreza todo o resto da Analítica Transcendental. ${ }^{18}$

O fato de o filósofo de Frankfurt partir dos conceitos kantianos para elaborar sua teoria do conhecimento torna evidente boa parte dos problemas que estão expressos na teoria do conhecimento de Kant. Entre tais problemas, se encontra a noção de coisa-em-si que, apesar de apenas servir - como nada que é, ou, fundamento do qual não se é possível conhecer - ao filósofo de Königsberg mais como uma noção performática -como estrutura formal que dá alicerce a sua doutrina - do que algo que existe em si, traz consequências graves para o seu sistema. Um desses problemas surge na tentativa de superação do Materialismo e Ceticismo por meio da noção de coisa-em-si, pois:

\footnotetext{
A superação de ambos, materialismo e ceticismo, não deve se dar pela mera postulação de uma coisa-em-si entendida como objetividade absoluta (ou objetividade do objeto), cuja cognoscibilidade possa ser dispensada no conhecimento da Natureza, mas pela demonstração de que todo objeto possível é sempre objeto para um sujeito, forma fundamental, segundo Schopenhauer, do princípio de razão suficiente. Isso significa que um "objeto incognoscível" não passa de noção vazia. ${ }^{19}$
}

A crítica ao sistema kantiano e seu objeto incognoscível, a coisa-em-si, nos leva a crer que a retomada de Schopenhauer a Berkeley - conservando suas diferenças - se dá no sentido de que aquele (Schopenhauer), ao invés de depositar o resultado de sua investigação no elemento "teológico metafisico", agarra com coragem a noção de que a coisa-em-si "deve ser pensada como livre não apenas de nossa estrutura cognitiva (o princípio de razão), mas também de qualquer relação causal com o fenômeno, que é nada além de sua aparência para nós e por nós conformada". ${ }^{20}$ Ademais:

Pode-se defender a hipótese de que, lendo Berkeley à luz da crítica kantiana e, assim, suprimindo os pressupostos teológicos, Schopenhauer pôde seguir um caminho distinto do de Kant, reformulando o idealismo transcendental de modo mais econômico, ou seja, dispensando toda a tortuosidade da arquitetônica (e seus inconvenientes) sem deixar de prover a proposta berkeleyana dos elementos suficientes à sua liberação do dogmatismo cristão. $^{21}$

Realidade (Wirklichkeit), um fazer-efeito, nesse sentido, não é nada mais do que minha representação. Isto é, ela é a efetiva apresentação daquilo que ao sujeito se presenta. Não obstante, faz-se necessário recordar que com o termo representação (Vorstellung) o filósofo de Frankfurt quer indicar algo como colocado (Stellung) diante de (Vor). Contudo, surge aqui um problema: se a

\footnotetext{
${ }^{18}$ MORAIS, 2018, p. 47.

${ }^{19}$ Ibidem, p. 47.

${ }^{20}$ Ibidem, p. 58.

${ }^{21}$ Ibidem, p. 59.
} 
realidade é o correlato da representação, faz-se necessário esclarecer o que é a representação para que possamos apreender o conceito de realidade. É nesse sentido que, segundo Morais (2018), a representação, isto é, “a Vorstellung consiste em fazer do objeto intuído na consciência uma coisa real no mundo externo, não como causa dessa intuição no sentido corrente, mas como o projetado e exposto diante de nós segundo as formas do tempo e do espaço". ${ }^{22}$

Quer dizer, nesse jogo - que é uma volta em si-mesmo - o objeto que ora se presenta para o sujeito e no sujeito é, na verdade, não algo fora, pertencente a algum mundo externo, mas aquilo (objeto) que é participe do próprio sujeito a partir das formas do princípio de razãa: tempo, espaço e causalidade. Isso implica dizer que para Schopenhauer toda realidade é apenas realidade pelo, para e no entendimento.

O mundo como representação é, nesse caso, o resultado do entendimento. Afinal, para este autor, o "entendimento une espaço e tempo na representação da matéria, isto é, propriedade de fazer-efeito. Este mundo como representação, da mesma forma que se dá apenas pelo entendimento, existe também só para o entendimento". ${ }^{23}$

Não obstante, vale ressalvar que, apesar de na frase de abertura de seu Magno Opus "o filósofo seguir a definição kantiana de transcendental ao dizer: 'O mundo é minha representação (Vorstellung)'. Porém esse estar-colocado-diante-de pressupõe um sujeito que intui. O mundo é representação de quem representa". ${ }^{24}$

Desse modo, se na tradição filosófica o ser recebe o sentido de realidade (Realität) e os seus fundamentos ganham status de substancialidade, na filosofia de Schopenhauer nem ser tem substância - pois não está submetido ao conceito de causalidade mecanicista, fisicalista ou teleológica -, nem é substrato de realidade, mas apenas efetividade (Wirklichkeit), um fazer-efeito. Sendo a representação, segundo o filósofo, movida pela vontade e mundo, e, por sua vez, a realidade uma manifestação do entendimento, os desdobramentos do problema da realidade ganham esses contornos, quer dizer, a questão das condições de possibilidade da realidade são fornecidas pelo aclaramento da questão do entendimento, esclarecida pelas noções de vontade e mundo.

\section{O "Realismo ingênuo" e a demonstração fenomênica de Ser e Tempo sobre a questão da possibilidade de um "mundo exterior"}

\footnotetext{
${ }^{22}$ Ibidem, p. 49.

${ }^{23}$ SCHOPENHAUER, 2005, p. 54.

${ }^{24}$ BARBOZA, 2003, p. 26.
} 
$\mathrm{O}$ que chamamos de realidade exterior ou o problema do mundo exterior talvez careça de problematização por parte da chamada ingenuidade da "locomotiva-cotidiana". Em meio a concep̧̧ão habitual tomamos a palavra realidade como sinônimo de algo externo, concreto, verdadeiro, visível, palpável, a qual se pode comprovar por meio de mero exame visual, gustativo, olfativo ou tátil.

Sem muito se ater à questão de como a noção de realidade chegou até nós de modo tão atrapalhado, é possível compreender que a sedimentação do "conceito de realidade" se estabeleceu a partir da falta de esclarecimento filosófico, quer dizer, pela falta de indagação filosófica, por parte dos modos vulgares do "pensar" cotidiano.

Assim, a chamada realidade, enquanto qualidade daquilo que se acha real - a partir dos estilhaços que chegaram até nós por meio da tradição filosófica e que se divide e se despedaça por meio dos hábitos superficiais das opiniões cotidianas - se mostra costumeiramente ao dizermos: real é aquilo que se apresenta diante de nós, fora de nós, fora de nossa mente, e que, portanto, existe.

Ao dizer assertivamente: o computador está sobre a mesa; não afirmo outra coisa senão: ele existe, é duro, largo, baixo, pesado, liso, etc. Em outras palavras: para a "opinião pública”, real, ou aquilo que possui realidade, é o mundo concreto: reunião de todos os objetos que de fato estão fora de mim; podem ser vistos, apalpados, sentidos, tocados e, por isso, não participam do âmbito da idealidade, ou do que concerne aquilo que chamamos de mundo interno, mas que na verdade reside fora de nossa mente ou consciência. Em oposição à chamada realidade dizem-se que é fantasia ou ilusão, uma miragem.

Tal crendice, denominada de realismo ingênuo ou de realismo de senso comum, não se faz de outro modo que não pelo que se diz da "concretude" da nossa "fé perceptiva". Ou seja, na crença de que as coisas nas quais depositamos certeza de sua "existência" são abalizadas por meio dessa fé que ganha sustentação através daquilo que assim percebemos.

Esta dita "fé perceptiva" estaria - por mais que velada ao "olhar" cotidiano - em total verossimilhança com a teoria de que verdade é aquilo que possui uma essência na concordância e que está ligada ao intercurso da representação como percepşão e seu correlato de realidade.

Retomando o exemplo acima, ao olharmos para o computador em nossa frente, asseveramos que de fato nossa percepção concorda com aquilo de que a representação “computador" é, e assim lhe atestamos certeza de verdade. O real para a opinião comum é, nesse caso, o que existe fora da mente e aquilo por meio do qual um significado, proposição, sensação e representação atestam sua veracidade.

Que o exame cotidiano revele que a realidade tem parentesco com o que existe fora de nós e que, por sua vez, faça-se crer nessa "meia verdade" não tem outro motivo senão o de que nossa tradição de pensamento metafísico nos legou um tipo de compreensão da realidade que está muito 
próxima da verdade tomada pela concepção que a filosofia concedeu à realidade. Quer dizer: em virtude de o ser receber o sentido de realidade e os seus fundamentos ganharem status de substancialidade que tal fenômeno chega a nós de modo atravessado.

Assim, real se apresenta para o cotidiano como aquilo que existe de fato "fora de nós" e que podemos tomar como verdade a partir de sua "visibilidade". Em oposição à realidade, nesse caso, é tudo aquilo que está dentro de nós e que costumeiramente chamamos de consciência ou ideia.

A partir de tal má interpretação do fenômeno "realidade", a dualidade da res cogitans (coisa pensante) enquanto aquilo que ficou conhecido como parte, isto é, como sujeito expresso por meio da res extensa (matéria), ou seja, pelo objeto do conhecimento, nunca ganhou tanta força.

No campo da Literatura, a questão da "possibilidade do mundo exterior ou realidade externa" surge como resquício de um a tradição de pensamento metafisico cara a alguns escritores. A título de exemplo, em sua obra 1984, o escritor George Orwell testemunha o legado deixado pela tradição metafísica ao escrever:

No fim o Partido haveria de anunciar que dois mais dois são cinco, e você seria obrigado a acreditar. [...] Além da validade da experiência, a própria existência da realidade externa era tacitamente negada por sua filosofia. [...] Se tanto o passado como o mundo externo existem apenas na mente, e se a própria mente é controlável - como fazer então?25

No contexto da obra, o "Partido" ou o "Grande Irmão" - símbolo do poder totalitário - age de modo a manipular toda a população por meio do controle das suas mentes. O resultante disto seria o fato de que realidade, para esta "filosofia", se reduz àquilo de que a mente produz em seus objetos; é por meio do controle da mente que se controla toda a realidade.

Apartando da presente discussão a gama de questões e problemas denunciados na passagem citada do livro de George Orwell, podemos acenar para o fato de que - em se referindo aos estudos filosóficos mais recentes - dentro desse "aspecto" ou dimensão da intepretação da realidade externa muitos são os posicionamentos, entretanto, nos limitaremos a alguns comentários da passagem do $\int 43$ tratado de 1927, Ser e Tempo, na qual o pensador alemão, Martin Heidegger, tece uma sutil crítica ao problema e "escândalo" da "realidade como problema do ser e da possibilidade de comprovação do 'mundo externo"':

Kant chamou de "escândalo da filosofia e da razão humana em geral" que ainda não se
dispusesse de uma prova definitiva, capaz de eliminar todo ceticismo a respeito da
"presença (existentia, Dasein) das coisas fora nós". Ele mesmo propõe uma prova,
fundamentando o seguinte "teorema": "A simples consciência (Bewusstsein) de minha
própria presença (existentia), determinada empiricamente, comprova a presença (existentia)
dos objetos no espaço fora de mim. [...] Kant pressupõe a diferença e o nexo entre "em
mim" e "fora de mim" - o que é faticamente correto, mas incorreto no sentido a que

${ }^{25}$ ORWELL, G. 1984. São Paulo: Companhia das Letras, 2009, p. 100. Grifo nosso.

Cadernos Cajuína, V. 5, N. 1, 2020, p. 165-177.

ISSN: 2448-0916 
tende a sua prova. Com isso, porém, não se comprova que o que se estabeleceu a partir do tempo sobre o ser simplesmente dado em conjunto do que se transforma e do que permanece também diga respeito ao nexo entre o "em mim" e o "fora de mim". Mas mesmo que se visse o todo da diferença e o nexo entre "dentro" e "fora", pressuposto na prova, e se concebesse ontologicamente o que nessa pressuposição é pressuposto, ainda ruiria a possibilidade de se considerar como necessária e ainda ausente a prova da "presença (existentia) das coisas fora de mim". O "escândalo da filosofia" não reside em essa prova ainda inexistir e sim em sempre ainda se esperar e buscar essa prova. Tais expectativas, intenções e esforços nascem da pressuposição, ontologicamente insuficiente, de algo com relação ao qual um "mundo" simplesmente dado de comprovar-se independente e exterior. ${ }^{26}$

O trecho acima é um exemplo de como, no âmbito da filosofia contemporânea, o problema da "possibilidade da comprovação de um mundo exterior" é um tanto problemática. Por isso, quando Heidegger questiona a frase do filósofo alemão Imannuel Kant sobre o "escândalo da filosofia", ele lembra-nos que o verdadeiro escândalo é a tentativa de querer provar essa possibilidade ${ }^{27}$.

Não obstante, com esse questionamento, o pensador da "floresta negra" nega a própria possibilidade da realidade ser, ela mesma, dada no exterior ou interior. Ou seja, de que ela possa acontecer "dentro" ou "fora" do humano (Dasein). Em outras palavras: no final das "contas" o que Heidegger questiona é a possibilidade de ser a realidade, interior ou exterior.

Entrementes, o "problema da realidade exterior", pensada pela tradição metafísica, desconsidera o fato de que todo o humano - como nos esclarece o pensador no tratado Ser e Tempo - desde sua queda no "nada" já é um ser-no-mundo. Tal constatação implicaria dizer que, desde já, somos junto às coisas e com os outros. Por isso a "realidade" não estaria dentro de cada um (no entendimento), mas junto ao Dasein que cada um de nós, em cada caso, somos. Ela nem estaria "fora de mim" nem muito menos "dentro de mim", mas acontece no "aî" (Da), isto é, na abertura efetivamente fenomênica.

Retomando a passagem do livro do George Orwell, é válido dizer que, a partir da mostração fenomenológica apresentada por Heidegger em Ser e Tempo a chamada a realidade não aconteceria no âmbito da mente - isto é, no entendimento, como havia pensado o filosofo frankfurtiano Arthur Schopenhauer -, mas como é ela mesma fenomênica, toda espécie de manipulação da massa - por parte do "Grande Irmão" ou do "Partido" - também não se daria por meio de uma manobra de "alienação da mente ou entendimento", mas sim através das distorções e manipulação dos fenômenos concebidos pela esfera do que o pensador alemão chamou de o "impessoal" (Das

\footnotetext{
${ }^{26}$ HEIDEGGER, M. Ser e Tempo. Petrópolis: Vozes. 2009, pp. 271 a 274. Grifo do autor.

${ }^{27}$ Para a questão do "problema" da realidade exterior, conferir Ser e Tempo, parágrafo 43 e sobre a questão da realidade em Kant ver: Crítica da Razão Pura. Lisboa: Calouste Gulbenkian, 2001. Para a passagem sobre o "escândalo da filosofia" consultar prefácio da segunda edição, p. B XXXV.
} 
Mann), cuja estrutura, segundo as descrições fenomenológicas de Ser e Tempo, perpassa o "modo fundamental de ser da cotidianidade", isto é, da decadência ${ }^{28}$ um tanto tentadora, tranquilizadora e alienante (Entfremdend).

Nesse sentido, seja pelo viés da interpretação do "conceito de realidade" apregoado pelo impessoal cotidiano ou, pela supressão da noção de realidade enquanto âmbito da questão em Kant, Heidegger demonstrará que o ser-no-mundo, isto é, o Dasein, como "ser-em" um mundo com os entes que vem ao seu encontro e junto aos outros, acontece na esfera da abertura de sentido enquanto desvelamento da fenomenalidade de mundo e cuidado (Sorge).

Trocando em miúdos, isto implica dizer que, muito antes da "realidade", efetivo é a possibilidade. Esta, convertida em poder-ser manifesta-se fenomenicamente ao Dasein por meio da articulação temporal da estrutura do cuidado (Sorge) cujo caráter de possível se abre a partir da significância propriamente constitutiva da totalidade do todo estrutural do mundo.

Em outras palavras, isto quer dizer que a suposta apreensão da "realidade do mundo exterior" é sempre tardia em relação ao ser-no-mundo e cuidado (Sorge). E isso porque o Dasein não "apreende" a "realidade" por meio dos objetos ditos exteriores, mas antes, pelo modo mesmo da disposição (Stimmung) concernentes à estrutura do cuidado atrelada ao ser-no-mundo.

Do mesmo modo, as noções de "dentro de mim" e "fora de mim" - também delineadas pela posição kantiana quanto à questão da realidade - "caem por terra" pois, depois da descoberta da noção de "abertura" enquanto "ấ” (Da) onde o Dasein acontece, parece extremante "perfurocontuso" falar de uma suposta "interioridade" ou "exterioridade". E isso porque o "aí" ( $D a$ ) se apresenta como uma espécie de localidade (Topos) ou lugar onde tanto o Dasein como também o mundo e a historicidade temporalmente acontecem. Dasein, mundo e historicidade, nesse sentido, são sempre temporais e, portanto, obedecem, cada um em cada caso, as suas dinâmicas de temporalização e temporalidade junto a totalidade do todo estrutural; não permitindo uma estrutura ontológica como: algo "dentro de mim" ou "fora de mim", mas sempre ek-staticamente junto às coisas e aos outros. ${ }^{29}$

\section{Considerações finais}

\footnotetext{
${ }^{28}$ Antes de mais nada, é válido ressalvar que "este termo não exprime qualquer avaliação negativa. Pretende apenas indicar que, numa primeira aproximação e na maior parte das vezes, o Dasein, está junto e no "mundo" das ocupações. Este empenhar-se e estar junto a... possui, frequentemente, o caráter de perder-se no caráter público do impessoal". (HEIDEGGER, 2009, p. 240. Grifo do autor.).

${ }^{29}$ No caso do Dasein - em se referindo as estruturas de mundo e historicidade (Geschichtlichkeit) - por meio de sua dinâmica de temporalização horizontal e no caso do Dasein humano, em sua dinâmica ekstática de temporalização vertical.
} 
O trabalho acima exposto ocupou-se de recolocar a manobra do pensamento dos pensadores Artur Schopenhauer e Martin Heidegger quanto à questão de como se efetiva a "realidade" levantada por esses dois autores.

Nesse sentido, na primeira parte do trabalho ilustramos parte dos esforços do filósofo frankfurtiano, Arthur Schopenhauer, quanto a sua posição sobre a noção de "realidade" (Wirklichkeit) operada pelo entendimento.

Em seguida, acenamos para o como se dá a noção de realismo ingênuo para o dia a dia do senso comum cotidiano; seu ponto de culminância na literatura e seu contraponto a partir da análise de Ser e Tempo quanto à questão do "mundo exterior" e seu status de "realidade" ou "efetividade".

Em termos de "resultados" podemos considerar que, em se tratando dos elementos essenciais para com a questão da realidade, em Schopenhauer obtemos alguns dos esclarecimentos sobre a sua doutrina. Afinal, certo é dizer que o filósofo de Frankfurt cercou o então "escândalo da filosofia" da prova dos objetos fora de nós; retoma o filósofo Berkeley; corrige Kant e estabelece um outro olhar quanto a esse "problema" da questão da realidade exterior dentro da Teoria do Conhecimento.

Não obstante, no período contemporâneo, o pensador alemão Martin Heidegger demonstra a fenomenalidade tardia da "realidade" por meio da noção de ser-no-mundo atrelando o fenômeno da efetividade à própria dimensão do Dasein enquanto ser-junto ao mundo antecedido pela estrutura geral do cuidado (Sorge). 


\section{REFERÊNCIAS}

BARBOZA, JAIR. A metafisica do belo de Arthur Schopenhauer. São Paulo. Humanitas, 2001. Modo de conhecimento estético e mundo em Schopenhauer. Trans/Form/ Ação, (São Paulo), v.29(2), 2006, p. 33-42.

Schopenhauer. Rio de Janeiro. Zahar, 2003.

HEIDEGGER, M. Gesamtausgabe (Obras Reunidas), Frankfurt: Série. Ed. Klostermann.

Sein und Zeit. GA 02. Frankfurt: Série ed. Klostermann, 1977.

Wegmarken. GA 09. Frankfurt: Série ed. Klostermann, 1976.

Ser y Tiempo. Trad. Jorge Eduardo Rivera C. Santigo de Chile: Editorial

Universitaria, 1997.

Ser e Tempo. Petrópolis: Vozes. 2009.

KANT, Immanuel. Crítica da razão pura. Lisboa: Calouste Gulbenkian, 2001.

MORAIS, DAX. O idealismo transcendental segundo Schopenhauer: de Berkeley para além de Kant. In: Rev. Filos., Aurora, Curitiba, v. 30, n. 49, p. 42-63, jan./abr. 2018.

SCHOPENHAUER, A. O mundo como vontade e como representação - tomo apresentação, notas e índices de Jair Barboza. - São Paulo: Editora UNESP, 2005.

Fragmentos sobre a história da filosofia - Precedido de Esboço de uma história da doutrina do ideal e do real. São Paulo. Martins Fonte, 2007.

ORWELL, G. 1984. São Paulo: Companhia das Letras, 2009. 